\title{
Reflexões sobre a responsabilidade sócioambientalempresarial e a segurança jurídica: notas introdutórias sobre a Teoria Discursiva do Direito $^{1}$
}

Carolina Vieira Ribeiro de Assis Bastos²

\section{Resumo}

\begin{abstract}
O presente trabalho tem por escopo debater no âmbito da Teoria do Direito, a questão ambiental, tendo em vista a necessidade de uma ação positiva e urgente de toda a sociedade. Primeiramente, discorrer-se-á sobre a possibilidade de superação da tensão entre desenvolvimento e proteção ambiental, apontando algumas contribuições da teoria discursiva do Direito de Jürgen Habermas. Em seguida, apresenta a referida teoria e defende seu viés emancipatório, quando levanta o envolvimento de todos os setores da sociedade na criação do Direito e na formação das decisões ecológicas. Ressalta ainda o papel da empresa e do consumidor nesse processo. Por fim, submete a teoria ao problema da segurança jurídica.
\end{abstract}

Palavras-Chave: Proteção ambiental; Teoria discursiva; Segurança jurídica.

\section{Introdução}

A tomada de consciência da crise ambiental é deflagrada a partir da constatação de que as condições tecnológicas, industriais e formas de organização econômica estão em conflito com a vida humana. Posicionar-se diante desta conflituosidade significa propor uma nova forma de desenvolvimento econômico tendo em vista a proteção do meio ambiente como elemento integrante deste novo modelo.

Neste contexto se insere a proposta deste trabalho, de abordar o tema da responsabilidade sócio-ambiental empresarial na perspectiva da Teoria Discursiva do Direito, tendo como objetivo último ressaltar suas implicações com a tão almejada segurança jurídica.

Primeiramente, apresentar-se-á o debate entre desenvolvimento econômico e proteção do meio ambiente, buscando a superação dessa dicotomia. Em seguida, será feita

\footnotetext{
1 Artigo apresentado na disciplina Teoria Geral do Direito, no 10 semestre do ano de 2006, do Programa de Mestrado em Direito da Universidade Estadual de Londrina, sob a supervisão da Profa. Dra. Marlene Kempfer Bassoli.

2 Mestranda em Direito Negocial pela Universidade Estadual de Londrina.
} 
uma breve explanação da Teoria Discursiva do Direito e suas possíveis conseqüências no âmbito da responsabilidade social empresarial.

Por fim, relacionar-se-á o trabalho com o tema da segurança jurídica, indispensável em qualquer discussão que se pretenda jurídica.

\section{A possibilidade de superação da tensão entre o modelo atual de desenvolvimento econômico e a proteção do meio ambiente}

A crise ambiental configura-se num esgotamento dos modelos de desenvolvimento econômico e industrial experimentados. Isto porque, o modelo proveniente da 1a Revolução Industrial e que se perpetuou nas seguintes, que prometia o bem-estar para todos não cumpriu seu intento, pois em que pese os benefícios tecnológicos trouxe em seu bojo a devastação ambiental planetária (LEITE, 2003, p. 22).

A problemática ambiental questiona os processos econômicos e tecnológicos que estão sujeitos à lógica do mercado, tanto que há quem defenda que crescimento econômico e defesa do meio ambiente são inconciliáveis. Neste sentido, vem a calhar a contribuição de Lourival Vilanova, que distingue a ideologia do progresso da ideologia do desenvolvimento. Segundo o autor, a ideologia do progresso é a ideologia do Estado Liberal, que significou o mínimo de Estado e o máximo de liberdade individual para a busca do crescimento econômico, o qual se restringia basicamente ao aspecto mercadológico. Em contrapartida, a ideologia do desenvolvimento é típica do Estado de Bem Estar Social, no qual a conquista de direitos sociais exprime um processo de desenvolvimento que é multifacetado, isto é, envolve aspectos que transcendem o econômico, como o laboral, educacional, tecnológico, científico, ecológico e, inclusive o direito à efetiva participação na gestão dos problemas sociais (VILANOVA, 2003, p. 485-486).

A crise ambiental suscita a necessidade de introduzir reformas no Estado, incorporando normas no comportamento econômico capazes de dissolver as externalidades sociais e ecológicas negativas geradas pela racionalidade do capital. No citado processo de desenvolvimento, o Estado assume um novo papel, o de agente direto neste processo. Entretanto, ressalta-se a necessidade de despertar a sociedade civil para a participação responsável no processo de desenvolvimento, visto que a proteção do meio ambiente não é 
somente tarefa do Estado, mas dever de todos, assim preceitua o art. 225 da Constituição Federal.

Diante disto, justifica-se o interesse pela teoria habermasiana. Para explicar as sociedades contemporâneas, Habermas fez uso de um instrumental conceitual: como as noções de mundo da vida e sistema. O mundo da vida é o horizonte dos fatos, do saber não problematizado da prática cotidiana, um acervo de conhecimento compartilhado. Já a idéia de sistema baseia-se na análise de que o sistema social, o qual tende ao equilíbrio autoregulativo, possui diferenciações funcionais em sub-sistemas. Partindo desses dois conceitos da teoria social contemporânea, o filósofo de Frankfurt constrói uma sociedade articulada em dois níveis: da integração social e da integração sistêmica. A primeira se dá no mundo da vida, é mediada por valores, normas e pela consciência dos indivíduos, na qual se insere a ação comunicativa. Já a integração sistêmica parte de uma lógica própria, independente dos sujeitos, na qual as ações se organizam formalmente e são determinadas por cálculos interessados; sendo que hoje cristalizou-se em dois sub-sistemas: o político e o econômico, cujos meios de integração são respectivamente poder e dinheiro (VELASCO, 2000, p. 20-23).

A racionalidade comunicativa pressupõe que os participantes possam chegar, por manifestações de apoio ou crítica, a um entendimento acerca do saber que deve ser considerado válido para o prosseguimento da interação, ou seja, as convicções intersubjetivamente compartilhadas vinculam os sujeitos em termos de reciprocidade. Já na racionalidade estratégica, o ator não vê no companheiro da interação um sujeito com o qual seja possível estabelecer um acordo intersubjetivo, busca somente o êxito com relação a fins que projetou sob o seu exclusivo ponto de vista (BOUFLEUER, 2001, p. 26).

Segundo Velasco (2000, p. 24-26), o que preocupa Habermas é a chamada colonização do Mundo da Vida, que consistiria na subordinação deste aos imperativos da lógica própria dos referidos sub-sistemas. Com este processo, não somente se enterram as formas de vida tradicionais, mas também se destrói a infraestrutura comunicativa daquelas esferas nas quais os homens não têm mais remédio, senão atuar em conjunto. Não é difícil advertir uma barbárie como conclusão lógica da completa absorção do Mundo da Vida pelos processos sistêmicos, já se percebe uma hegemonia da racionalidade instrumental nas formas de vidas dos cidadãos que estão cada vez mais monetarizadas e burocratizadas. 
No entanto, ainda há resquícios de uma comunicação livre de distorções, por isso, está implícito o convite a empreender o processo contrário, de descolonização do Mundo da Vida, evitar que os indivíduos se isolem dos mecanismos sociais de tomadas de decisões e da própria gestão da sociedade. O Direito, enquanto sistema de coordenação de ações de sujeitos autônomos deve pressupor em algum momento uma ação comunicativa orientada ao entendimento.

Segundo Velasco (2000, p. 79), com a Teoria Discursiva do Direito, Habermas relegou ao Direito o papel de mediador entre a faticidade da política e da economia e a validade normativa da moral, ou seja, uma função de "dobradiça" entre um Mundo da Vida integrado simbólica e normativamente e uma esfera sistêmica regida pelo poder e pelo dinheiro.

Neste sentido, a idéia de desenvolvimento duradouro, sustentável, busca um paradigma diferente da racionalidade econômica que tem predominado. Ao sustentar a satisfação das necessidades presentes sem pôr em risco as gerações futuras e sendo completada pela teoria habermasiana, vislumbra a possibilidade de superação da tensão existente entre desenvolvimento e proteção ambiental através do envolvimento dos cidadãos como sujeitos autônomos e partícipes da sociedade, portanto responsáveis.

\section{A Teoria Discursiva do Direito}

A Teoria Discursiva do Direito ${ }^{3}$ de Habermas representa um viés emancipatório, na medida em que se compromete com uma concepção radical de democracia. Conforme se demonstrará, não se limita a descrever as normas vigentes, mas propõe critérios para a resolução de problemas de legitimidade.

Em "Direito e Democracia: entre Faticidade e Validade", ao adotar o modelo da linguagem para o Direito, Habermas almeja esclarecer a estrutura discursiva comum do

3 Vallespín (1997, p. 203) explica a função do direito nesta teoria através de uma metáfora. Segundo o autor, Habermas parece ter redescoberto um manancial de água, o qual está contido nos princípios universalistas da Constituição e que permite a exaltação de uma comunidade de homens livres e iguais sob o Direito. A tarefa do Direito consistiria em justamente transladar esta água a todos os âmbitos sociais mediante um eficaz sistema de condução, que evitaria a desertificação de importantes zonas sociais e as imunizaria dos fluxos de outras fontes contaminadas, como a política e a economia. Devido à finitude deste manancial de águas cristalinas, ele deve ser renovado permanentemente com a água de outros poços e o meio encarregado de velar por este permanente bombeio é o sistema democrático e, sobretudo, a ação de uma opinião pública responsável e inquieta. 
direito e da moral, para mostrar que só uma validação intersubjetiva das normas jurídicas, que apela simultaneamente para a liberdade subjetiva dos indivíduos e para a autodeterminação democrática das comunidades, é capaz de conferir legitimidade ao direito positivo (SHUMACHER, 2004, p. 87).

Segundo Habermas (1997, p. 132-133), se por um lado, a conduta consciente da pessoa singular mede-se pelo ideal de auto-realização, por outro lado, a eticidade de formas de vida coletiva baseia-se em utopias de uma convivência não alienada e solidária, bem como por modelos de uma sociedade mais justa, na qual as instituições busquem regular os comportamentos no interesse simétrico de todos os envolvidos. Neste sentido, os direitos humanos e a soberania do povo formam as idéias que ainda possibilitam uma justificação do direito moderno. "O visado nexo interno entre soberania do povo e direitos humanos reside no conteúdo normativo de um modo de exercício da autonomia política, que é assegurado através da formação discursiva da opinião e da vontade, não através da forma das leis gerais e abstratas" (HABERMAS,1997, p. 137).

Se os discursos constituem a formação de uma vontade racional, o almejado nexo interno entre soberania popular e direitos humanos somente será possível se o sistema dos direitos institucionalizar as formas de comunicação. Neste sentido, conclui Habermas (1997, p. 139): "A substância dos direitos humanos insere-se, então, nas condições formais para a institucionalização jurídica desse tipo de formação discursiva da opinião e da vontade, na qual a soberania do povo assume figura jurídica".

Portanto, da aplicação do princípio do discurso ao Direito resulta que somente podem reclamar validade aquelas normas jurídicas que encontram o assentimento de todos os membros da comunidade jurídica em um processo discursivo de criação do Direito que, há de ser constituído legalmente através de procedimentos. Ao final, a racionalidade dos procedimentos se transforma nas condições sob as quais tem lugar as discussões e a avaliação dos resultados (VALLESPÍN, 1997, p. 213).

Além disso, Habermas estabelece uma complementariedade entre Direito e Moral, que revela uma natureza do Direito como mecanismo capaz de reduzir a complexidade da sociedade e favorecer os processos de integração social. Em outras palavras, o Direito consegue elevar a um nível de reflexão superior o que no Mundo da Vida aparece difuso e disperso e, das três fontes de integração social que o filósofo menciona- dinheiro, poder e 
solidariedade- o Direito se localizaria junto com a ação comunicativa dentro desta última categoria (VALLESPíN, 1997, p. 216).

Assim, a aliança entre o Direito e Ação Comunicativa vai ressaltar a multifuncionalidade que para Habermas há de assumir o Direito, dirigido não somente à satisfazer as demandas de legitimação, mas também a de integração social.

Cabe ressaltar ainda que, o modelo habermasiano recai em grande medida sobre processo informais, mantém o princípio da representação parlamentar, mas acentua a esfera pública, assentada sobre a sociedade civil, que são aqueles espaços livres da interferência estatal e deixados à espontaneidade social não regulada pelo mercado.

Porém, Velasco (2000, p. 84) desconfia que a força civilizatória do Direito seja capaz por si só de prestar articulação interna às diversas formas de vida, assim como incentivar na vida social uma sólida cultura participativa. As regulações jurídicas podem proteger os valores cívicos da vida em sociedade, mas o Direito não pode engendrar uma cultura política democrática, sempre dependerá que esta o fomente, o facilite e lhe dê contexto.

Daí a importância da discussão acerca do papel da empresa enquanto ator social, que deve também estar inserido no Mundo da Vida e não somente no sub-sistema econômico.

\section{A responsabilidade sócio-ambiental empresarial}

Atualmente, debate-se com intensidade o papel desempenhado pelas empresas no processo de desenvolvimento com justiça social. Verifica-se uma transição no modo das empresas pensarem suas estratégias e missões dentro da comunidade devido a um conjunto de fatores históricos, dentre os quais está a crescente preocupação com o meio ambiente. Esta preocupação das empresas na promoção do desenvolvimento ambiental sustentável denominar-se-á responsabilidade sócio-ambiental empresarial.

Segundo Félix (2003, p. 19-20), a responsabilidade social empresarial consiste na iniciativa espontânea das empresas de contribuir para uma sociedade melhor e um meio ambiente mais limpo, as quais transcendem as obrigações legais. Assim, os critérios de avaliação do sucesso começam a incorporar dimensões que vão além da organização econômica, referem-se também à vida social, cultural e à preservação ambiental e, o 
conceito de eficiência não significa mais somente seguir as regras do mercado, mas também princípios éticos.

A responsabilidade social não se expressa como uma ação emergencial pontual, mas sim como uma perspectiva em longo prazo e de consciência das empresas, que incorporam em sua cultura e na mentalidade de seus dirigentes e colaboradores a busca do bem-estar da população tendo em vista que o desenvolvimento da organização depende da sociedade à qual pertencem (FÉLIX, 2003, p. 35).

Sob o aspecto formal, as empresas e dirigentes abordam a responsabilidade empresarial em uma declaração de princípios ou código de condutas norteadoras de suas atividades, que revelam seus objetivos e valores. No entanto, cabe à empresa traduzir tal responsabilidade em estratégias e atitudes cotidianas de fato, que coloquem em prática tais objetivos e valores. Por isso, além de manter órgãos de avaliação permanente de sua gestão social, deve também promover formas de consulta à comunidade (FÉLIX, 2003, p. 37).

Fabião (2003, p. 46) considera a relação empresa-sociedade hierarquizada e pouco dialógica. Aponta ao fato de que a entrada das empresas no setor social ainda carece da preocupação com uma cidadania participativa, há uma instrumentalização da ética em termos de objetivos estratégicos e a interação da sociedade ainda é pautada pela falta de um diálogo democrático.

Neste contexto, emerge a necessidade de diferenciação entre gestão estratégica e gestão social. A primeira é um tipo de ação utilitarista, fundada no cálculo de meios e fins e implementada pela interação de duas ou mais pessoas na qual uma delas tem autoridade formal sobre as outras, ou seja, o sub-sistema empresa imerso no sub-sistema econômico determina suas condições de funcionamento. Já a gestão social, busca um gerenciamento mais participativo, dialógico, no qual o processo decisório seja exercido por meio de diferentes sujeitos sociais (FABIÃO, 2003, p. 57).

Portanto, enquanto a interação empresa-sociedade se configurar de maneira paternalista através da determinação unilateral de apoio a projetos sociais estar-se-á referindo à ação estratégica. A ação social será comunicativa quando a empresa, enquanto membro da comunidade, responda pelos seus atos e oriente sua ação com pretensões de validade intersubjetivamente reconhecidas. 
No que se refere à temática do presente trabalho, esperar uma ação social da empresa em questões ambientais é mais do que necessária face aos problemas que surgem em escala mundial e numa velocidade que foge ao controle do homem.

Mas para que isto se torne um ciclo, o comportamento das empresas deve ser completado pelo dos consumidores. Portanto, tendo em vista que a formação desse ciclo de responsabilidade social exige laços de cooperação fortes, esta não deve ser bandeira e objetivo apenas das empresas, mas também do Estado e da própria sociedade civil, por isso, é necessário permitir que os vários atores organizados da sociedade também dêem sua contribuição.

Para um novo modelo de empresa e de gestão dos negócios, o consumidor assume um papel indispensável de mediador entre um Mundo da Vida estruturado normativamente e o sistema econômico. Segundo Fabião (2003, p. 60), a valorização da ética nos negócios por parte do consumidor é exercício de cidadania. É necessário o reconhecimento do poder do consumidor, que não é meramente econômico, no sentido de discordar das práticas sociais das empresas e contribuir efetivamente para a modificação deste modelo.

\section{A inevitável questão da segurança jurídica}

Qualquer proposta de inovação no âmbito do Direito não pode se furtar da submissão ao problema da segurança jurídica. Existem algumas exigências mínimas que precisam ser cumpridas, pois do contrário não se estará referindo à idéia de Direito.

Segundo Vegas (2004, p. 19), a segurança jurídica é um conceito histórico e se encontra intimamente vinculada à noção de Estado, de tal forma que pode-se falar de três modelos de relação entre segurança jurídica e justiça.

O primeiro modelo é de identificação entre segurança jurídica e justiça, típico do Estado Absoluto. Trata-se de um conceito amplo, o Direito proporciona segurança jurídica simplesmente pela sua existência. O segundo modelo é o do Estado Liberal, com uma acepção muito mais restrita de segurança jurídica, esta é um valor que somente alguns ordenamentos jurídicos realizam e não se identifica necessariamente com a idéia de justiça. Neste, um Direito seguro é um Direito baseado em normas gerais, claras, eficazes, onde não se confia a resolução de conflitos ao subjetivismo judicial, mas à procedimentos préestabelecidos e normas conhecidas (VEGAS, 2004, p. 19-20). 
O terceiro modelo apresentado é o de coordenação entre segurança jurídica e justiça, o qual mais interessa ao presente trabalho. Este se inicia com o estabelecimento do Estado Social, o qual devido à uma inflação de normas regulamentares tendo em vista setores concretos de cidadãos, estaria sujeito à influência e pressão de alguns setores sociais, implicando a perda de segurança jurídica. Isto porque, o Estado Social haveria violado os fundamentos do Estado de Direito, quando reforçou a importância legislativa do executivo teria atentado contra a separação de poderes, pressuposto básico do Estado de Direito (VEGAS, 2004, p. 23-24).

Esta afirmação teria procedência se a segurança jurídica ainda tivesse como pressuposto a separação entre Direito e Moral, ou entre Direito e sociedade. No Estado Social, esta separação se dilui na medida em que se orienta por razões de justiça material. Neste sentido Vegas (2001, p. 25) entende que:

\footnotetext{
Um modelo de coordenação significa que não é legítimo para a segurança jurídica vulnerar a justiça, que ambos são valores desejáveis e alcançáveis, ou seja, que por difícil que seja localizá-la, há uma base comum a ambos valores. Os caminhos ensaiados para essa conciliação são vários: ver a segurança jurídica como uma condição necessária para a realização de justiça, considerá-la como uma parte da própria justiça etc.
}

Segundo Novoa (2000, p. 31-32), um conceito de segurança jurídica proveniente de uma versão puramente liberal do Estado de Direito, que tutela somente interesses individuais, impede atribuir ao ordenamento a consecução de determinado fins e trata-se de uma formulação negativa. No Estado Social, a intervenção do Estado para efetivar os direitos de caráter econômico e social, exige um conteúdo social à ação pública. A tutela de interesses gerais permite ao Estado configurar-se como instrumento de integração social, o que legitima uma idéia de segurança jurídica mais positiva.

Nas sociedades em processo de desenvolvimento acelerado verifica-se a necessidade de maior interveniência do Estado. O desenvolvimento requer planejamento, investimentos que ultrapassam a capacidade econômica dos particulares. Segundo Vilanova (2003, p. 468-469), é, sobretudo, o Estado que tem condições de assumir a empresa do desenvolvimento global, integral, racionalizado.

Além disso, numa sociedade em desenvolvimento há uma experiência constitucional, ou seja, a lei é uma técnica de experimentação sobre o mundo das inter- 
relações humanas. Por isso, a proteção jurisdicional dos direitos não se exerce com um grau esperado de certeza jurídica. Esta advém de normas que possibilitam a previsão da conduta dos indivíduos e dos agentes do poder, característica principal do Estado de Direito, o qual elimina a irracionalidade nas decisões do poder e nas relações recíprocas dos indivíduos. Segundo Vilanova (2003, p. 471), devido a isto, a crise do Estado pode ser interpretada como um aspecto parcial da crise total da sociedade e avaliada em termos de decréscimo de segurança jurídica.

No que tange à questão ecológica, exige-se a imposição de um modelo de coordenação entre segurança jurídica e justiça, ou em outras palavras, uma concepção positiva de segurança jurídica.

Segundo Vallespín (1997, p. 213), o paradigma procedimental do direito proposto por Habermas, pode resultar na superação das deficiências do paradigma liberal clássico e do próprio Estado Social. Ao primeiro se imputa um interesse unidimensional por salvaguardar a liberdade em sua concepção negativa, que não atende as assimetrias econômicas e sociais. De outro modo, o paradigma do Estado Social compartilha desse mesmo objetivo de satisfazer a autonomia individual, com a diferença de que agora busca estabelecer o acesso eqüitativo aos bens necessários para sua realização.

No entanto, o problema do Estado Social é que está presente uma contradição entre fim e método, pois quando estabelece formas de vida eqüitativas deixando espaço à auto-realização, por outro lado, o faz mediante programas políticos, que ao invés de potencializar a dimensão participativa dos cidadãos em conformidade com uma vontade coletiva, cria verdadeiros clientes das burocracias-estatais. Há uma colonização do Mundo da Vida por parte do sistema administrativo, que de modo algum favorece a autonomia individual ou coletiva. A atual democracia de massas acaba se restringindo à mera gestão administrativa das prestações do Estado Social, por isso, não pode furtar-se da acusação de paternalismo e carência de controles democrático-comunicativos (VALLESPÍN, 1997, p. 214).

O modelo de Estado Democrático de Direito corresponderia a superação do Estado Social ao reconhecer o papel do Estado enquanto ator do processo de desenvolvimento, mas também apostar na esfera pública, que tem sede na sociedade civil que deve ser livre das interferências sistêmicas. No entanto, a crítica que se faz e a preocupação que se levanta com relação à segurança jurídica é: como pode o Direito assumir o papel de garantidor da 
unidade do sistema social e canalizador de interesses não privados se não se dão os pressupostos comunicativos tão exigentes para a criação do Direito? Seria esta uma teoria que não se ajusta a realidade e portanto, fadada ao fracasso?

Estes e outros problemas são bem expressivos e de difícil resposta, mas há de se ter em mente a contribuição da teoria habermasiana no sentido de ressaltar a constante necessidade de que os cidadãos se responsabilizem por seu próprio destino, que no caso da questão ecológica é mais do que urgente. Apostar em procedimentos de participação da formação da vontade e da opinião em matéria ambiental relegaria a todos e não somente ao Estado a tarefa de criar um modelo de coordenação entre segurança jurídica e justiça e, aqueles que agem em nome de si próprios tendem a não cometer injustiças ao contrário daqueles que agem em nome de outrem.

\section{Conclusão}

O movimento mais importante e surpreendente que Habermas produziu em "Faticidade e Validade" foi colocar o Direito como o "guarda" mais qualificado para submeter e disciplinar os meios dinheiro e poder. Neste sentido, o Direito seria capaz de traduzir as mensagens que Ihe chegam pela via da linguagem corrente de uma forma compreensível para os sistemas político e econômico, ou seja, funcionaria como um transformador da circulação comunicativa da sociedade entre sistema e Mundo da Vida.

No que tange ao problema ambiental é necessário o despertar da sociedade civil, pois envolve questões materiais de existência. Hoje, qualquer desenvolvimento que se busque deve ser compatibilizado com o equilíbrio ecológico e a construção de um plano de sociedade mais elevado com os preceitos de justiça e democracia, revela a importância da luta pelos direitos e meios de participação democrática que transcendem os positivados no texto constitucional.

A efetividade da participação social depende de alguns procedimentos: democratização da sociedade; processos pedagógicos que impliquem a conscientização da cidadania e do respeito ao meio ambiente, sobretudo, instrumentos jurídicos de garantia dos direitos fundamentais.

Cabe ressaltar ainda, que a problemática ambiental surge num contexto de crise da democracia representativa, que não consegue mais atender às expectativas. A democracia 
não pode mais se desenvolver no contexto de delegação de responsabilidade formal do povo para seus representantes. É preciso criar formas refinadas de mediação entre a sociedade civil e os órgãos estatais e neste sentido a teoria habermasiana pode contribuir, quando aponta para o envolvimento de todos os atores sociais, inclusive a empresa, no processo de criação do Direito.

Quanto à questão da segurança jurídica, a teoria tem que se submeter a crítica de que procedimentalizar a formação da opinião e da vontade pode criar um número indeterminado de interpretações a ponto de inviabilizar a criação do Direito, mas por outro lado, um modelo positivo de segurança jurídica depende do envolvimento de todos.

O mérito e a importância desse debate teórico é que uma discussão profunda sobre o Direito, sempre contém a possibilidade de alcançar uma nova e eficaz forma de realizar ideais, como o de uma sociedade ecologicamente sustentável.

\section{Referências}

BOUfLEUER, José Pedro. Pedagogia da Ação Comunicativa: uma leitura de Habermas. 3. ed. ljuí: Editora Unijuí, 2001.

FABIÃO, Maurício França. O negócio da Ética: um estudo sobre o terceiro setor empresarial. In: BARALDI, Gustavo (Org.). Responsabilidade Social da Empresas: a contribuição das universidades. São Paulo: Peirópolis: Instituto Ethos, 2003. v. 2.

FÉLIX, Luiz Fernando Fortes. A conjuntura atual e a responsabilidade social e cidadã das empresas. In: BARALDI, Gustavo (Org.).Responsabilidade Social da Empresas: a contribuição das universidades. São Paulo: Peirópolis: Instituto Ethos, 2003. v. 2.

HABERMAS, Jürgen. Direito e Democracia: entre faticidade e validade. Trad. Flávio Beno Siebeneichler. Rio de Janeiro: Tempo Brasileiro, 1997.

LEITE, José Rubens Morato. Dano ambiental: do individual ao coletivo extrapatrimonial. 2. ed. São Paulo: Revista dos Tribunais, 2003.

NOVOA, César Garcia. El princípio de seguridad jurídica en materia tributaria. Madrid: Marcial Pons, 2000.

SCHUMACHER, Aluisio A. Sobre Moral, Direito e Democracia. Lua Nova - Revista de Cultura e Política, p. 75-96, n. 61, 2004. 
VALLESPÍN, Fernando. Reconciliación a través del derecho? Apostillas a facticidad y validez de Jürgen Habermas. In: GIMBERNAT, José Antonio (Ed.). La Filosofía Moral y Política de Jürgen Habermas. Madrid: Biblioteca Nueva, 1997.

VEGAS, Jesús Luis Castillo. Tres modelos posibles de relación entre la seguridad jurídica y la justicia. Crítica, v. 9, n. 29/30, abr./out. 2004.

VELASCO ARROYO, Juan Carlos. La teoría discursiva del derecho: Sistema Jurídico y democracia en Habermas. Madrid: Boletín Oficial del Estado y Centro de Estudios Políticos y Constitucionales, 2000.

VILANOVA, Lourival. Escritos Jurídicos e Filosóficos. São Paulo: AXIS MVNDI: IBET, 2003. v. 2. 
Revista de Direito Público, LondRINA, V. 2, N. 1, P. 185-198, JAN./ABR. 2007. 